\title{
ESTRUCTURA ORGANIZACIONAL EN MATERIA DE SARLAFT
}

\subsection{Funciones de la junta directiva}

E ste órgano es el encargado de definir las políticas y medidas necesarias para el correcto ejercicio del objeto social de la empresa, por supuesto, dirigiendo todas sus actividades a prevenir que la compañía sea utilizada para la materialización de delitos relacionados con el lavado de activos y la financiación del terrorismo.

× Definir las políticas del SARLAFT.

× Crear y actualizar el código de ética en materia de SARLAFT.

× Ratificar el manual de SARLAFT y sus actualizaciones.

× Elegir al oficial de cumplimiento y su suplente.

× Sancionar los procedimientos para la vinculación de las personas que presentan un mayor riesgo de LA/FT, así como los responsables.

× Hacer monitoreo periódicamente sobre el perfil de riesgo de LA/FT de la empresa e informar sobre los hallazgos.

$\times$ Emitir un concepto respecto de cada uno de los puntos que contengan los informes que presente el oficial de cumplimiento, dejando la expresa constancia en la respectiva acta.

× Emitir un concepto respecto al contenido de los informes presentados 
por el oficial de cumplimiento y emitir las observaciones, recomendaciones, sugerencias y oportunidades de mejora que se requieran.

* Definir y autorizar los recursos técnicos y humanos indispensables para conseguir un correcto funcionamiento del SARLAFT.

$\times$ Establecer los criterios objetivos y definir los procedimientos y las instancias responsables de la identificación y reporte de las operaciones sospechosas.

* Implantar las metodologías y procedimientos para la correcta realización de entrevistas para la vinculación de clientes, sean estas presenciales o no.

× Diseñar las metodologías de segmentación, identificación, medición y control del SARLAFT.

× Elegir las instancias autorizadas para exonerar clientes del diligenciamiento del formulario de transacciones en efectivo

× Escoger las instancias responsables del diseño de las metodologías, modelos e indicadores cualitativos y/o cuantitativos de reconocido valor técnico para la oportuna detección de las operaciones inusuales.

× En el caso de grupos empresariales, la junta directiva de aquella que sea la matriz o controlante deberá establecer los lineamientos y acoger las medidas necesarias para que cada una de las subordinadas o filiales del grupo apliquen los mismos modelos acogidos por la matriz, adaptándolos, por supuesto, al objeto social de cada una.

\subsection{Funciones del representante legal}

Las actividades que debe realizar el representante legal en materia de SARLAFT son las siguientes:

× Proponer, en coordinación con el oficial de cumplimiento, a la junta directiva el manual de procedimientos del SARLAFT y sus actualizaciones.

* Comprobar que los procedimientos definidos desarrollen todas las políticas adoptadas por la junta directiva.

$\times$ Analizar los resultados de las mediciones de riesgos para así identificar los perfiles, factores, riesgos asociados y acoger las medidas de mitigación.

× Acreditar el cumplimiento de los parámetros normativos en el diseño e implementación de las bases de datos y plataformas informáticas e la empresa. 
× Suministrar todos los recursos humanos y tecnológicos necesarios para un eficiente funcionamiento del SARLAFT.

$\times$ Apoyar en todo lo que se requiera al oficial de cumplimiento.

× Avalar que la información utilizada en el SARLAFT cumpla con los requisitos exigidos por la ley y las autoridades competentes.

× Ratificar el correcto diseño del manual SARLAFT y las funciones que se realizan para su ejecución.

\subsection{Requisitos y funciones del oficial de cumplimiento $^{6}$}

\subsubsection{Requisitos del oficial de cumplimiento}

× Tener capacidad decisoria y en la estructura jerárquica estar como mínimo en un cargo de segundo nivel.

× Contar con conocimientos amplios en materia de SARLAFT debidamente certificados.

× Contar con un equipo humano y tecnológico suficiente para suplir las necesidades propias del SARLAFT dentro del área de cumplimiento.

$\times$ No ser parte de los órganos de control o áreas que tengan por función la ejecución de actividades propias del objeto social de la compañía.

× Estar vinculado laboralmente a la empresa.

× Haber oficializado su posesión ante la Superintendencia Financiera de Colombia.

Todos los requisitos antes relacionados también deben ser satisfechos por el oficial de cumplimiento suplente. 


\subsubsection{Funciones del oficial de cumplimiento}

En materia de SARLAFT, el oficial de cumplimiento debe ejecutar las siguientes funciones:

* Velar por el correcto funcionamiento del SARLAFT y realizar todas las actividades necesarias para que este proceso sea oportuno, eficiente y efectivo.

* Elaborar, presentar y sustentar trimestralmente ante la junta directiva el informe sobre los resultados de su gestión. Los temas que, como mínimo, debe contener el informe son los siguientes:

- Los resultados de la aplicación de cada una de las etapas del SARLAFT.

* Los indicadores de atención y resolución a requerimientos emitidos por autoridades competentes.

* El diagnóstico de los perfiles de riesgos y sus factores, al igual que sus indicadores de evolución individual y consolidada, los controles a ellos aplicados y sus resultados.

* Las mediciones de efectividad de los controles, instrumentos, mecanismos de mitigación de riesgos y de la operatividad del SARLAFT (fallas detectadas y controles aplicados).

* El informe de los resultados de la aplicación de los controles sugeridos por la junta directiva.

* La presentación de todas las actualizaciones en materia normativa que hayan sido emitidas por órganos de control, la Unidad Administrativa Especial de Información y Análisis Financiero - UIAF o entidad competente.

* Fomentar la aplicación de las medidas de control y correctivos al SARLAFT.

* Organizar y estructurar los planes de capacitación dentro de la compañía y ejecutarlos.

* Proponer la necesidad de realizar actualizaciones del manual SARLAFT e iniciar los planes para su divulgación.

* Esbozar las técnicas para la detección de operaciones inusuales junto con sus indicadores (cualitativos o cuantitativos), metodologías y modelos.

* Valorar de manera detallada los informes de auditoría interna presentados por la revisoría fiscal e iniciar todos los planes y estrategias necesarias para fortalecer el SARLAFT y sus mecanismos de detección en lo relacionado con las debilidades halladas. 
* Trazar las metodologías de segmentación, de identificación, de medición y control en materia de SARLAFT.

- Producir los criterios objetivos para la identificación de operaciones sospechosas y ponerlos a consideración para aprobación ante la junta directiva o el órgano que haga sus veces. De igual manera, someter ante este órgano las operaciones inusuales detectadas para la aplicación de sanciones o correctivos.

* Remitir en los tiempos establecidos los informes a la UIAF.

* Tomar la decisión sobre la vinculación de clientes PEP y definir los procedimientos de seguimiento y monitoreo para cada uno de estos.

* Determinar la existencia de operaciones sospechosas.

\subsubsection{Obligaciones de los empleados y prestadores de servicios en materia de SARLAFT}

Todos los empleados y personal externo de la compañía deben cumplir con:

× El código de comportamiento o de conducta.

× El manual SARLAFT y los demás documentos anexos o complementarios a este.

× Dar resolución a los requerimientos remitidos por el oficial de cumplimiento, así como las demás solicitudes que este les haga en materia de cumplimiento del SARLA/FT.

× Comunicar de manera inmediata al oficial de cumplimiento, o a los miembros del área de este, sobre el conocimiento de actividades que generan alerta en materia de LA/FT.

$\times$ El cumplimiento de las obligaciones en materia de SARLAFT está por encima de la ejecución de las actividades propias del objeto social de la compañía para todos los miembros de esta. 


\subsection{Comité para la prevención de lavado de activos}

Es recomendable a la administración la conformación de un comité integrado por un número impar de miembros de áreas gerenciales y directivas, con la finalidad de asignar funciones y responsabilidades en materia de SARLAFT, y para que adelanten todo lo concerniente con la definición, gestión, control y aplicación de este.

\subsubsection{Elementos mínimos del reglamento del comité}

El reglamento del comité debe cubrir los puntos siguientes:

Figura 3.16. Elementos mínimos del reglamento del comité

Los objetivos y
responsabilidades. Los requisitos de sus
miembros.
El periodo de vigencia del comité.
Numero y clase de reuniones.

Fuente: elaboración propia

\subsubsection{Objetivos y responsabilidades recomendadas}

× Ejercer como apoyo a los órganos de administración, dirección y control en materia de prevención de la ocurrencia de eventos de LA/FT.

× Constituir canales de comunicación asertiva con los órganos de administración, dirección, control y auditoría en todo lo relacionado con la ejecución del SARLAFT y el SARO para verificar de manera permanente su estado. Dicho flujo de comunicación debe permitir verificar:

* El estado de resultados de las gestiones alentadas por el área de cumplimiento, revisoría fiscal, contraloría interna y gerencia operativa.

* Verificar la existencia de nuevos mercados y sus riesgos inherentes (señales de alerta).

- La calidad y eficiencia de los controles de SARLAFT.

* El acompañamiento a los órganos directivos de la empresa en materia de SARLAFT.

Este comité es de libre nombramiento y remisión por parte de la junta directiva conforme a los resultados de su gestión. 


\subsubsection{Funciones sugeridas}

$\times$ Vigilar de manera permanente que las metodologías, controles, procedimientos $y$, en fin, toda la estructura del SARLAFT, esté conforme a los parámetros establecidos en las normas vigentes, emitidas por las autoridades competentes, y cumplan con su objetivo de mitigar la ocurrencia de riesgos.

× Propender por la implementación de controles necesarios y eficientes que prevengan que la empresa sea usada para la comisión de delitos relacionados con LA/FT haciendo seguimiento al funcionamiento del área de cumplimiento.

× Mantenerse en permanente actualización de la normatividad vigente relacionada en materia de prevención de lavado de activos y financiación del terrorismo, y hacer la divulgación de ello en las áreas en las que sea necesario.

× Deliberar acerca de la implementación del SARLAFT y hacer imperativo su cumplimento dentro de la compañía.

× Auxiliar al oficial de cumplimiento en todo lo que este requiera para una correcta implementación del SARLAFT.

\subsubsection{Reuniones sugeridas}

Por lo menos una vez cada tres meses, sin embargo, el oficial de cumplimiento podrá citar a reuniones extraordinarias cuando lo considere necesario y pertinente.

Todos los temas tratados dentro de las reuniones del comité deben constar en acta, al igual que las recomendaciones, oportunidades de mejora, sugerencias y planes de acción que se acuerden. 